\title{
The Application of Balanced Score Card in PPP Project
}

\author{
Di Wu \\ School of Business \\ Beijing Institute of Fashion Technology \\ Beijing, China \\ 514043137@qq.com
}

\author{
Weixia $\mathrm{Wu}$ \\ School of Business \\ Beijing Institute of Fashion Technology \\ Beijing, China \\ wu-weixia@263.net
}

\begin{abstract}
As a new type of financing model of project, PPP project has developed rapidly in recent years, which is mostly used in the field of infrastructure construction. The aim of this study is to build a system of balanced score card for evaluating the performance of PPP project. The paper lays particular emphasis on the selecting of indicators in the process of evaluating. Based on the strategic objectives of the PPP project, we build a balanced scorecard system from the four dimensions of finance, customer, internal process, learning and growth with relatively independent third party as the evaluation subject and sets the evaluation index. The balanced scorecard system we build takes financial and non-financial elements into consideration and carries out a comprehensive evaluation of benefits from the perspective of the project as a whole to promote the improvement of the performance level of PPP projects in the implementation process.
\end{abstract}

Keywords-PPP; balanced score card; performance evaluation

\section{INTRODUCTION}

PPP is the abbreviation of "Public Private Partnership", that is, the public-private partnership model which is mostly used for infrastructure. PPP originated from the PFI initiated by the British Conservative government in 1992. After five years of tepidness, the Labor Party took power in 1997, renamed the PFI as PPP and tried to make it a mutually acceptable policy. Then PPP was widely used around the world. The reason is that PPP can provide better infrastructure, public services, and contribute to the economic development of the city at a low cost and low risk without increasing the government's financial burden. The ultimate goal of the PPP is to achieve a win-win situation for the public sector, the private sector and service recipients. After the 18th CPC National Congress, governments at all levels have promulgated relevant policies and management measures to support PPP projects in a bid to gradually shift the PPP model from exploration to standardization. Since 2016, the demand for PPP projects has been constantly expanding, and the number of warehousing projects has exceeded 9,000, covering various fields such as municipal engineering, transportation and water conservancy construction. This long-term contractual relationship between the government and the enterprises not only relieves the financial pressure of government and provides more investment channels for social capital, but also improves the efficiency and effectiveness of infrastructure construction. From the point of view of the international public administration literature, the results of PPP performance are diverse, that is, some PPPs achieve the expected goals and some PPPs do not achieve their goals. This has led us to think about whether PPP evaluation is reasonable and how to evaluate PPP in a better way.

\section{Performance Evaluation System of PPP Project}

As a new type of project management mode, PPP model has its own characteristics such as huge investment, long franchise period and usually involving multiple shareholders' groups. Because of those characteristics the PPP project performance evaluation should have its own characteristics in selecting evaluation index and building evaluation index system.

\section{A. The Profit Model of PPP Project}

The PPP project itself must be a public welfare project, including a business project (a project paid by the user), a quasi-business and public welfare project. Because of the nature of public welfare projects, the rate of return of those projects is shortfall below the profitability of social capital chasing. For the government, PPP can solve such difficult problems as financing, debt and operation and management. From the perspective of society as a whole, it can increase the effective allocation of social resources. Social capital can be invested in public utilities and can be pursued in addition to the public utility projects themselves. The business profit related to projects is invested through investment-related projects (highprofit projects) so as to offset investment in PPP projects and subsidize operating costs and increase return on overall investment profits.

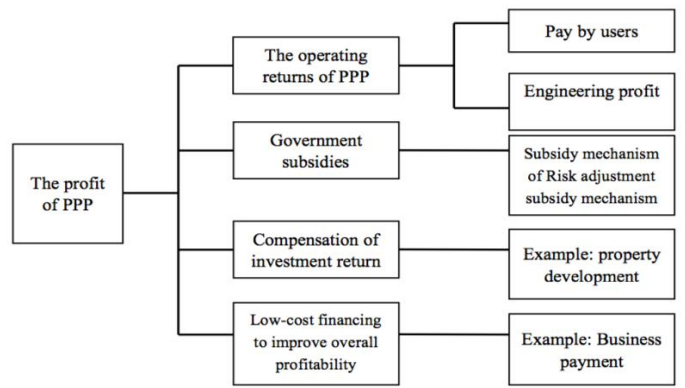

Fig. 1. The profit model of PPP project 


\section{B. The Performance of PPP Project}

There are two aspects to explain the PPP performance, a broad sense and a narrow sense. The narrow sense of PPP performance is to evaluate whether the contract or agreement goals are achieved and to consider more about the issue of return on investment. [1] The field of application of PPP includes not only the supply of infrastructure and public services, but also the fields of urban renewal and regional economic development (Hodge \& Greve, 2007). In the case of infrastructure PPP projects, the narrow sense of PPP performance can be explained as project performance. Project performance mainly examines project quality, project cost, efficiency, engineering disputes and other indicators. If the projects are mainly about economic development, the narrow sense of PPP performance can be interpreted as the tax revenue growth, employment rates and other issues.

For the broad sense of PPP performance, the evaluation objectives of PPP not only include the return on investment projects, as well as the short and long term impact brought by the projects. Value for money VFM is one of this kind of general performance evaluation. According to the domestic and foreign literature, VFM is the mainstream method to evaluate whether a PPP project is established or not. For example, there are two reasons why the London Metro PPP continues to advance. One reason is that PPP is able to ensure security and the other is that VFM is used in the performance assessment. However, judging from the existing literature, it is necessary to evaluate the PPP performance and set the evaluation index after operation by VFM. [2]There are variable indices such as the innovation of PPP, the quality of service, the cost, the reasonableness of risk allocation and so on. In addition, Klijn (2010) evaluates PPP performance in a broad sense. It includes not only outcome indicators such as innovation, efficiency, cost and effectiveness, but also process-oriented indicators such as frequency of interaction and conflict resolution.

However, the above evaluations are both singledimensional and linear. For example, making the assessment from the implementation life cycle of PPP, including the evaluation in implementation and the evaluation after implementation. However, there are multiple actors involved in PPP, and different actors appeal different interests, the existing PPP performance appraisal also needs to pay attention to this point.

\section{Application of Balanced Score Card in PPP Project}

From the perspective of stakeholder theory, the interests of PPP projects divide into three parts, the public sector, the private sector and the general public. Due to the diversity of stakeholders, in the evaluation process each of the stakeholders starts from the perspective of maximizing their own interests, it is difficult to get a consistent evaluation results. Government departments pay more attention to VFM maximization, controlling rate of project investment, quality satisfaction and related social effects. However, as the main part of evaluation the private sector is more concerned about the cost of project and income assessment. The main work of the private sector is pursuit of profit maximization. Therefore, the main part appraisal of PPP performance should be a third party appraisal agency which is relatively independent. It evaluates whether the strategic objectives of the project are achieved by standing in the perspective of the project with no preference of either party.

The Application of balanced scorecard in the evaluation of PPP performance for the projects can combine financial factors with non-financial factors to achieve evaluation purposes efficiently. There are four dimensions included in balanced scorecard, which are finance, internal processes, client, learn

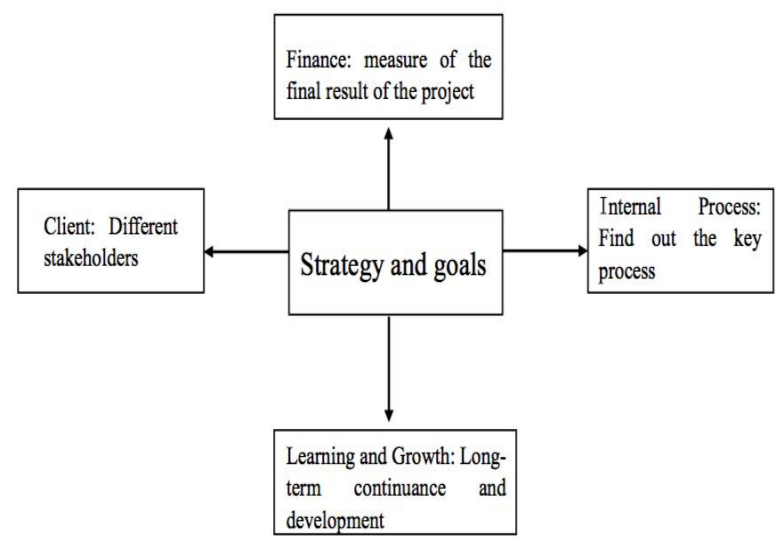

Fig. 2. The performance of PPP project

According to the strategic goal, the four dimensions are closely interrelated with each other and mutually restrained and promoted by each other. In order to achieve the strategic goal, it is necessary to consider whether the interests of different stakeholders can be realized at the client level at the beginning of the operating process of the project. In the constructing and operating process of the project, internal processes and financial aspects should be taken in the first consideration. In addition to the benefits brought by the project, whether the project can be sustained and whether the future target can be achieved are worth thinking.

\section{THE DESIGN FOR INDEX OF BALANCED SCORE CARD IN PPP PROJECT}

\section{A. Fiance}

In PPP projects, the financial indicators reflect the risks and rewards of the project. Financial indicators can measure the final results of project management. They are also concrete reflection of the results of cooperation of both parties. And financial indicators occupy a very important position in performance evaluation. Good performance of the project in the market can bring more benefits to the company of the project. Companies usually pay more attention to the payback period, return on investment and market share of the project. The government departments pay more attention to the project's VFM value, regulatory costs and financial subsidies.

\section{B. Client}

There are three areas in customer level, including government departments, the private sector, and the public sector. Conducting an integrated assessment from these three level is able to make up the imbalance of interests caused by 
the lack of evaluation of a single subject. The benefit of the project is reflected by the satisfaction of these three level of the project. The higher degree of satisfaction will bring more benefits for the project.

\section{Internal Process}

From the internal process, it is important to identify the key processes that affect the performance of project and consider the setting of indicators from both the construction period and operation period of the project and control the cost, progress, quality and safety of the project effectively. The objective of supervising and managing the entire operation process of the project, and reflecting the advantages and disadvantages of the project by the indicators measuring the internal process is to improve the efficiency of resource utilization and the rationality of resource allocation.

\section{Learning and Growth}

In the complex and volatile market environment, there are many factors related to success. And good learning and growth is one of the important factors for success. The learning and growth of PPP projects is mainly the innovation and continuity of the project. The innovativeness is reflected in the level of scientific research and investment in project construction. The growth is reflected in the sustainability of the project, including whether the two parties are willing to continue their cooperation, and factors such as the impact of environmental sustainability.

TABLE I. THE DESIGN FOR INDEX

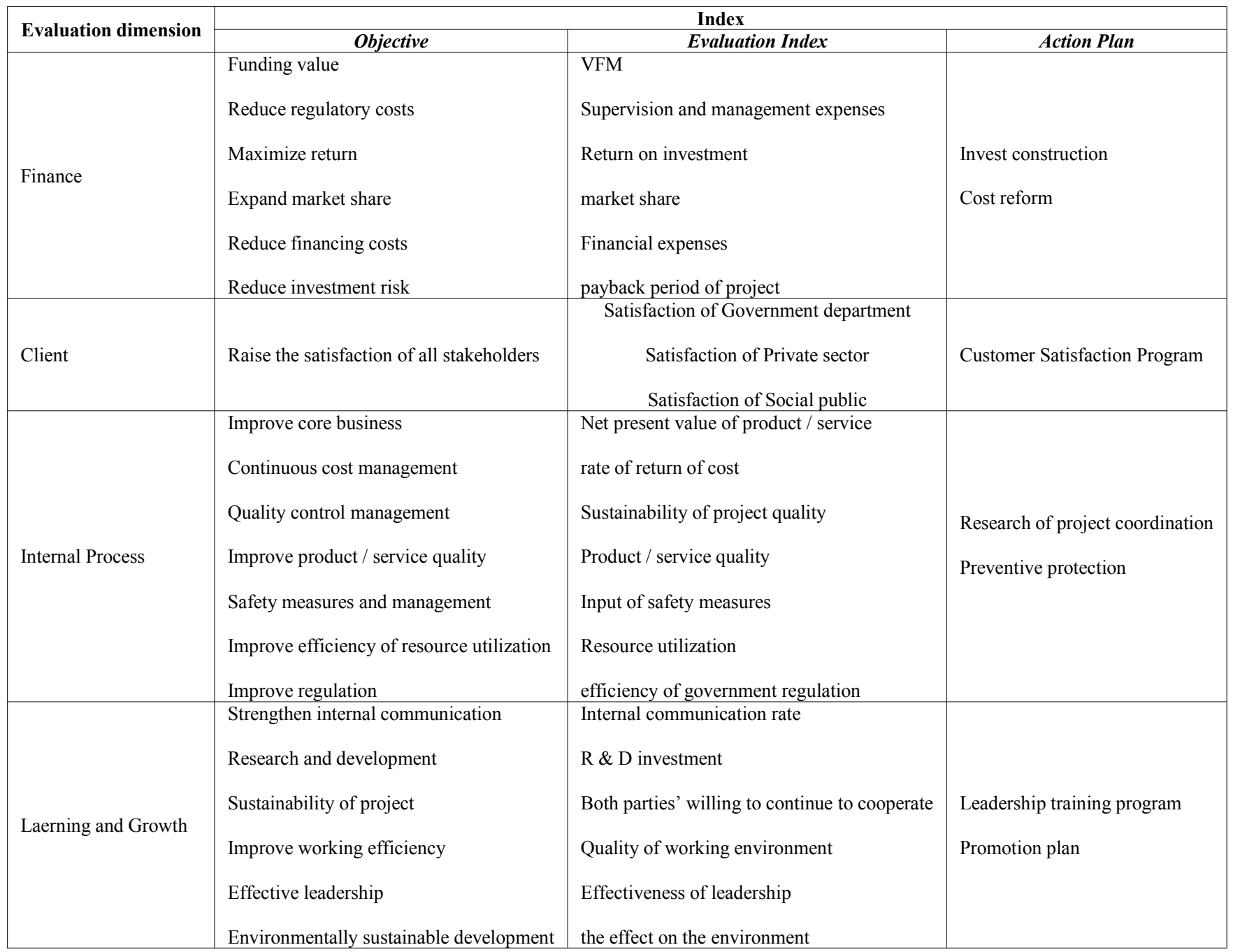

\section{CONCLUSION}

Although the balanced score card can be used skillfully as a tool for performance evaluation, the analysis and application of balanced score card in PPP projects needs to be further studied. In this paper, we apply the balanced score card system to the performance evaluation of PPP projects by using the independent third party as the evaluation entity. We set the evaluation indicators from the four dimensions of finance, customer, internal processes, learning and growth. This evaluation method that takes the interests of all parties into consideration reflect the cooperation of PPP project, which is the main idea of PPP project. And we also provide ideas and methods for the effective implementation of performance evaluation during the implementation of PPP projects. Of course, the use of balanced score card in PPP projects needs to 
be further improved and verified, such as the rationality of index selection and the feasibility of action plan.

\section{ACKNOWLEDGMENT}

My deepest gratitude goes first and foremost to Professor Weixia Wu, my supervisor, for her constant encouragement and guidance. She has walked me through all the stages of the writing of this thesis. Without her consistent and illuminating instruction, this thesis could not have reached its present form.

Second, I pleased to acknowledge my classmates for their invaluable assistance throughout the preparation of the original manuscript. They graciously make considerable comments and sound suggestions to the outline of this paper. Besides, I am extremely grateful for my roommates for their cooperation, comments, and wise advice, although their advice is not always taken, where faults and infelicities remain.
Last my thanks would go to my beloved family for their loving considerations and great confidence in me all through these years.

\section{REFERENCES}

[1] Graeme A. Hodge, Carsten Greve. "PPPs: The Passage of Time Permits a Sober Reflection," J.Economic Affairs, pp. 34-39, 2009.

[2] Steijn,B., E.H.Klijn, J.Edelenbos. "Public Private Partnerships: added value by organisational form or management?" J. Public Administration, vol. 89, pp. 1-23, 2011.

[3] Wang S Q. "Lessons learnt from the PPP practices in China (keynote speech)," Asian Infrastructure Congress 2006. Organized by Terrapinn and sponsored by IAPF, Hong Kong, Nov 29-30, 2006.

[4] Garrett Seepersad, Sunil Bisnath. "Challenges in Assessing PPP Performance," J. De Gruyter, pp. 205-122, 2014.

[5] Ken Harima, Suelynn Choy, Chris Rizos, Satoshi Kogure. "An Investigation Into the Performance of Realtime GPS+GLONASS Precise Point Positioning in New Zealand," J. De Gruyter, pp. 185-195, 2017.

[6] Yelin Xu, John F.Y.Yeung. "Developing a risk assessment model for PPP projects in China-Afuzzy synthetic Evalution Approach," Automation in Construction, pp. 929-943, 2010. 